\title{
Points of Interest
}

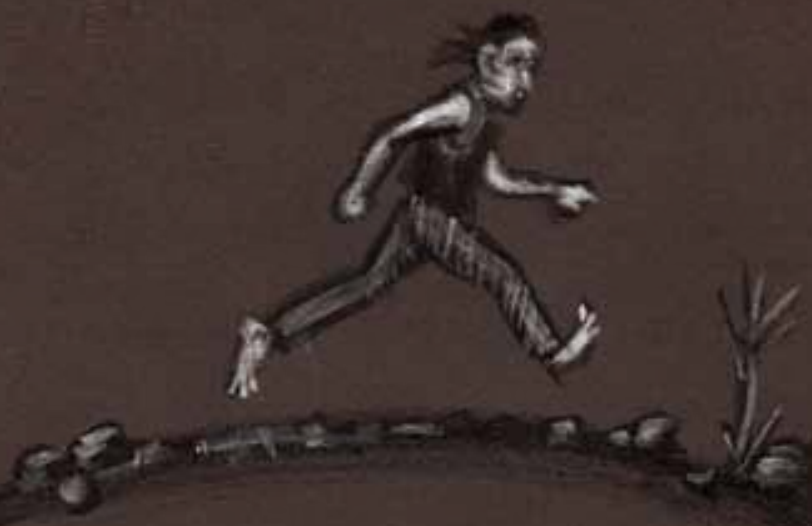

\section{The Human Body ls Built for Distance}

The conventional wisdom is that distance running leads to debilitating wear and tear, especially on the joints. But now a best-selling book has reframed the debate about the wisdom of distance running. In Born to Run (Knopf), Christopher McDougall, an avid runner who had been vexed by injuries, explores the world of the Tarahumara Indians of Mexico, a tribe known for running extraordinary distances in nothing but thin-soled sandals. McDougall makes the case that running isn't inherently risky. Instead, he argues that the commercialization of urban marathons encourages overzealous training, while the promotion of high-technology shoes has led to poor running form and a rash of injuries.

Tara Parker-Pope The New York Times October 26, 2009 http:// www.nytimes.com/2009/10/27/health/27well.html?_r=1

\section{Clean Smells Promote Moral Behaviour, Study Suggests}

People are unconsciously fairer and more generous when they are in clean-smelling environments, according to a study led by a Brigham Young University professor. The research found a dramatic improvement in ethical behaviour with just a few spritzes of citrus-scented Windex.

ScienceDaily October 26, 2009 http://www.sciencedaily.com/ releases/2009/10/091025091148.htm

\section{Employable Animals}

When most people think of working animals, they picture Seeing Eye dogs or farm animals. But there's a whole world of animals with jobs that are a little more ... unorthodox. Head-banging snakes are said to be able to feel and react to an oncoming earthquake 120 kilometres away and up to five days before it happens. Bees detect bombs by swarming the source of the chemicals after being trained to associate the smell with a food source. Dolphins use their natural echolocation to safely attach floating markers to underwater mines - the mines are then either avoided by ships or removed by Navy divers.

Reader's Digest http://www.readersdigest.ca/pets/ $\mathrm{cms} / \mathrm{xcms} / \mathrm{unexpected-employable-}$ animals_3302_a. html

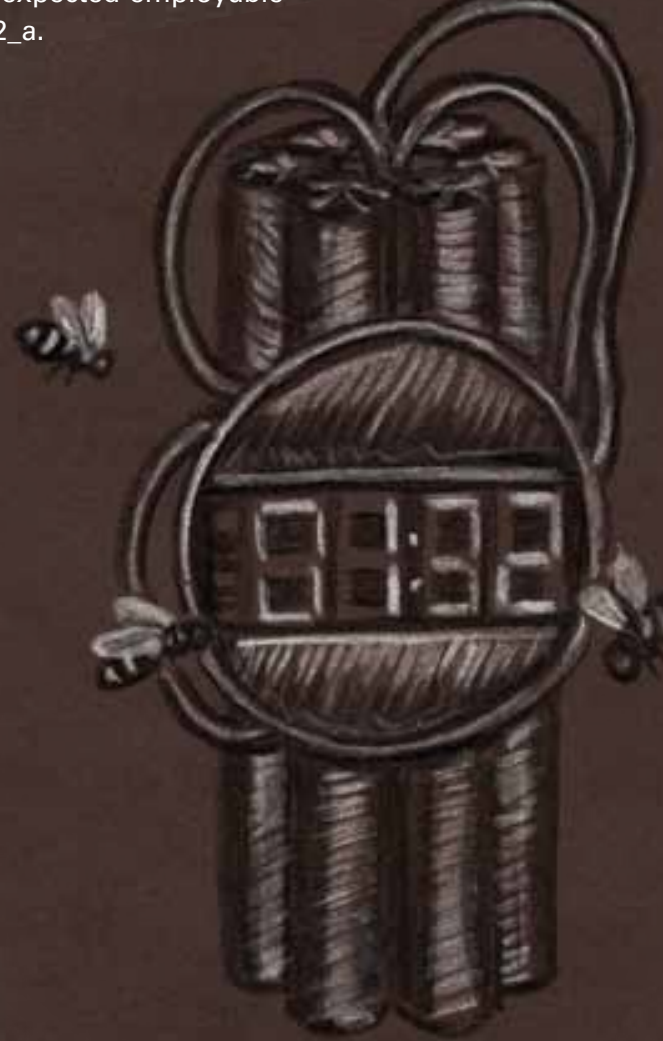




\section{Reversing the Brain Impairments Caused by Sleeplessness}

Researchers have identified the pathway in the brain that causes cognitive impairment when we haven't had enough sleep. Pennsylvania State University biologists and neuroscientists found that when mice were deprived of sleep, a particular enzyme built up in the brain's hippocampus. The hippocampus is the region of the brain linked to learning and the formation of memories.

"Millions of people regularly obtain insufficient sleep," said principal investigator Ted Abel. "Our work has identified a treatment in mice that can reverse the cognitive impact of sleep deprivation. Further, our work identifies specific molecular changes in neurons caused by sleep deprivation, and future work on this target protein promises to reveal novel therapeutic approaches to treat the cognitive deficits that accompany sleep disturbances seen in sleep apnea, Alzheimer's disease and schizophrenia."

David Pescovitz Boing Boing October 26, 2009 http://www. boingboing.net/2009/10/26/reversing-the-brain.html

\section{The Silverware Swallower}

A Dutch medical magazine asked its readers to send in their stories of strange medical cases. One respondent told the tale of Margaret Daalman, who came into the hospital 30 years ago complaining of a stomach ache. A radiograph

found 78 forks and spoons

inside her! The photos and radiographs were not made public until now.

Miss Cellania Neatorama October 29, 2009 http:// www.neatorama. com/2009/10/29/ the-silverwareswallower/

\section{Election Outcomes Affect Testosterone Levels in Men}

After the outcome of the US presidential election was declared, neuroscientists at Duke University found that although male voters for Barack Obama, the winner, had stable levels of testosterone, the hormone's levels rapidly dropped in males who had cast ballots for John McCain or Robert Barr, the losers. The researchers monitored testosterone levels from the saliva of 163 college-age volunteers in North Carolina and Michigan by asking them to chew sugar-free gum and then spit before and after the results were announced. The male participants would normally have shown a slight nighttime drop in testosterone levels anyway because the body doesn't need it during sleep; but on election night, they departed dramatically from this routine: Obama voters' levels did not fall as they should have, whereas those of McCain and Barr backers dropped more than would have been expected. No significant effects were seen in the 106 female volunteers.

Charles Q. Choi Scientific American October 23, 2009 http:// www.scientificamerican.com/article.cfm?id=vote-electiontestosterone

\section{Stem Cells from Fat Used to Grow Teen's Missing Facial Bones}

So far, stem cells have been used to mend tissues ranging from damaged hearts to collapsed tracheas. Now the multifaceted cells have proved successful at re-growing bone in humans. In the first procedure of its kind, doctors at Cincinnati Children's Hospital Medical Center replaced a 14-year-old boy's missing cheekbones - in part by re-purposing stem cells from his own body. The technique, should it be approved for widespread use, could benefit some seven million people in the United States who need more bone - everyone from cancer patients to injured war veterans.

Katherine Harmon Scientific American October 15, 2009 http://www.scientificamerican.com/ article.cfm?id=stem-cells-bone-growth 